\title{
Do Fiscal Rules Constrain Fiscal Policy in Romania?
}

\author{
Alina Daniela Vodă1, Gabriela Dobrotă², Loredana Andreea Cristea ${ }^{1}$, and \\ Bianca Ciocanea $^{1}$ \\ ${ }^{1}$ Lucian Blaga University of Sibiu, Department of Doctoral Studies, Victoria Boulevard 10, Sibiu, \\ Romania \\ ${ }^{2}$ Constantin Brâncuși University of Târgu Jiu, Faculty of Economic Sciences, Republicii 1, Târgu \\ Jiu, Romania
}

\section{Abstract}

At both macroeconomic and national level, in recent decades, European tax policies have shown a particular interest in addressing the spectrum of risk issues in terms of maturing the business environment and the lack of sustainable development of the economy. In Romania there has been a significant increase in public debt, which is increasingly threatening fiscal sustainability. This is due to fiscal rules that restrict the applicability of fiscal policy to balancing the national economy. However, fiscal

Corresponding Author: Alina Daniela Vodă alina.voda3@yahoo.ro

Received: 17 November 2019 Accepted: 6 January 2019 Published: 12 January 2020

Publishing services provided by Knowledge

(c) Alina Daniela Vodă et al. This article is distributed under the terms of the Creative Commons Attribution License, which permits unrestricted use and redistribution provided that the original author and source are credited.

Selection and Peer-review under the responsibility of the EBEEC Conference Committee. policy did not act in the direction of economic recovery during the crisis that started in the last quarter of 2008, which had a negative impact on the Romanian business environment. Objectively, fiscal policy should manifest itself as a general framework of the economy on the basis of which to develop fiscal rules that act in the direction of sustainable development of the business environment and implicitly, of socio-economic life. The research carried out referred to identify how fiscal rules in Romania restrict the application of fiscal policy as well as whether there is an explicit concordance between them. The research methodology aimed to use the ARDL model to apply the Granger causality test, using quarterly data for a set of four indicators, being identified that Romanian fiscal rules restrict fiscal policy. The achieved results highlighted the fact that fiscal rules restrict fiscal policy, being identified a long-run relationship between the analyzed variables and implicitly, a state of instability of the fiscal system in Romania.

Keywords: fiscal policy, autoregressive distributed-lagged model, Granger causality test.

JEL Classification: E62, E69, C13

\section{Introduction}

Among the main objectives regarding the applying fiscal rules there is macrostabilization of the economy. It aims to reduce the budget deficit, provide financial stability and fiscal sustainability. However, fiscal rules are based on fiscal policies aimed at directing and stimulating the entire economic evolution of a country through 
the cumulus of actions regarding tax enforcement and the determination of their role in the formation of budgetary revenues and the financing of budgetary expenditures. Fiscal policies must be perfectly harmonized with fiscal rules so as to ensure that revenue is collected as much as possible to the consolidated general budget, while encouraging the development of the business environment and investments. These issues can only be viable if they respect the principle of economic equity, since any income earned must contribute to forming the budget of the country. The fiscal policy will transpose, by way of legislation, the decisions implemented to balance the economy in the form of fiscal rules. A faulty decision will affect both the short and long term the whole process of developing an economy. It is imperative to implement a strategic plan that takes into account the specificity of the national economic environment as well as macroeconomic projections. In this paper we analyzed the hypothesis that the fiscal rules represent a constraint factor of the fiscal policy applied in Romania. In other words, we tried to know to what extent fiscal rules constrain the fiscal policy applied in Romania. The autoregressive distributed-lagged model (ARDL) was used to apply the Granger causality test on the four variables chosen as a result of the existing fiscal rules.

In order to better capture the implications of the implementation of the fiscal rules, this article is structured as follows: Section 2 Revision of the literature, Section 3 Adoption of fiscal rules in Romania, Section 4 Analysis of the fiscal rules effect on fiscal policy, Section 5 Conclusions, followed by bibliographic references.

\section{Literature Review}

The way fiscal rules influence fiscal policy has become an issue of interest in national and international research, especially in the post-crisis period. Based on epistemological presumptions that had in the foreground economic recovery and, implicitly, sustainable development, a broad spectrum of approaches were revealed in empirical research. Countercyclical policies motivated by Keyenes and procyclical fiscal policies have been an important subject in analyzing and identifying an optimal policy that responds to the needs of socio-economic life [7]. M.E. Bova, N. Carcenac and M.M. Guerguil analyze fiscal rules and fiscal policy procyclicality in developed countries, arguing that more flexible rules and more sustained institutional arrangements could help reduce procyclical prejudices associated with rules [1]. J.L. Combes, A. Minea and M. Sow analyze the cyclical responses of fiscal policy, conditional on public debt [3]. They said that the tax authorities' tendency to stimulate aggregate demand reduction or to counter the 
overheating trend of the economy is conditional on the level of public debt. Another approach to tax policies shows that the effects of pro-cyclical policy are greater in less developed economies [9]. Another perspective on the impact of fiscal policies on the economy was presented by Y. Suzuki [15]. In the paper presented, a dynamic stochastic general equilibrium model has been developed, which explains the differences in the cyclical characteristics of fiscal policy between developed and emerging countries, especially the consumption and pro-cyclical government consumption budget in emerging countries. A.G. Socol and R.M. Feraru concluded that a justification for the pro-cyclicality observed is that tax authorities can engage in promoting an anti-cyclical tax policy, but they do not have adequate information on current cyclical conditions, real-time indicators associated with the economic cycle are subject mainly due to the significant uncertainty of estimates of potential GDP revisions [16]. D. Šehović analyzed the impact of the large recession on fiscal and monetary policy in developed market economies [17].

Tax policies play an important role in determining fiscal rules. The latter must impose certain limits that protect the entire economy of a country. In this respect, a broad debate was conducted on the analysis of the effect of fiscal rules on fiscal policies and the economy. R.I. Dziemianowicz and A. Kargol-Wasiluk argued that the European Union fiscal policy coordination mechanism has not been fully effective in the sense that the instability of public finances in the European Union is probably due to institutional problems as well as the quality of the instruments used by accountability laws tax [4]. The authors of this paper substantiated their claim on the basis of public finance stability studies in the period before the economic crisis of 2008. T. Cordes, M. T. Kinda and M. P. S. Muthoora argued that expenditures rules can foster better spending behavior if solid government fund management systems are in place [2]. The result of their analysis reveals that the compliance rate for expenditure rules is higher than for budget rules, which are associated with lower levels of public investment in emerging market economies. B. A. Dumitrescu made an analysis of the evolution of fiscal rules in Romania, concluding that there is a need to reform the existing fiscal rules in Romania, especially as regards the consequences of non-compliance and the possible evacuation clauses, in order to maintain credibility a fiscal framework based on rules [5]. 


\section{Adoption of Fiscal Rules in Romania}

Knowing the national economic problems, included in a generalized, macroeconomic framework, will allow the creation of an overall picture and the identification of the determinants responsible for the destabilization of the economic environment. Sustainable development of an economy of a country economy is not only driven by endogenous factors, an important role being played by the fiscal instruments and rules used to harmonize cooperation between states.

The Maastricht Treaty, which entered into force on 1 November 1993, imposed a set of rules by applying external policies to lay the foundations for economic and monetary union. The purpose of this treaty was, besides social security elements, to provide regulations for compliance with financial and budgetary discipline. Through this Treaty, within a European framework, Member States must avoid excessive deficits. A commission set up at European Union level monitors developments in the budgetary and government debt situation in the Member States based on two criteria namely whether the current or planned deficit in gross domestic product exceeds a benchmark and whether the share of government debt in the domestic product the gross value exceeds the reference value, unless the weight decreases sufficiently and approaches the reference value at a satisfactory pace. These benchmarks are found in the same treaty, namely the Protocol on the excessive deficit procedure, which specifies a share of less than $3 \%$ of the current or planned deficit in gross domestic product at market prices as well as a lower share of $60 \%$ of government debt in gross domestic product at market prices. These fiscal rules are based on a sustainable generation of economic equilibrium in the Member States of the European Union. Thus, monitoring and enforcing fiscal rules at the level of national economies is not a barrier to the exercise of their own fiscal rules, but a discipline imposed precisely for their sustainable protection and development. A rule is in fact a norm that prevents decision makers from being involved in the development of tax policy decisions. By quantifying the number of fiscal rules it is possible to precisely quantify the objectives achieved by them. Romania did not have an effective fiscal discipline to set medium and long-term goals at national level. Political factors have had a significant influence, eluding economic sustainability. If Romania did not have the notion of "market economy" until 1989 due to the communist political regime oriented towards nationalization, the return to an economy with a competitive market did not show any remarkable progress after this time. In addition to the lack of entrepreneurial practice, decision-makers in Romania have not led the economy to progress and increased competitiveness. 
The year 2002 started with a decrease of the fiscal pressure due to the tax rate that was reduced from $38 \%$ to $25 \%$. The single tax rate of $16 \%$ was introduced only since 2005 , which favors the growth of production and exports.

Moreover, the entire privatization process has gone through a long and difficult period of more than a decade until it has been completed, leading to the bankruptcy of many large companies. However, economic growth of Romania was reflected in gross domestic product, which had an upward trend until 2007 inclusive.

A number of exogenous factors such as the economic crisis that debuted in the United States in the last quarter of 2008 have strongly influenced the global economic situation, including Romania. This year also represented a new stage in the development of the socio-economic life of Romania by accessing the European Union following the signing of the Treaty concerning the accession on 25 April 2005 in Luxembourg. The Treaty contains three general safeguard clauses, two of which refer to economic safeguarding and the Internal Market. In the context of the economic safeguard clause if Romania, by the end of three years of accession, had to face serious and persistent difficulties in a particular economic sector, it could request the authorization of European Commission to take protective measures to improve the situation and adjust economic sector of the Common Market. This authorization could also be requested by another Member State to take protectionist measures regarding the rebalancing of the Romanian economy. The Internal Market safeguard clause refers to an involvement of the European Commission on its own initiative or at the request of a Member State to redress the effective functioning of the Internal Market if Romania fails to meet its commitments. Thus, the clauses in the Treaty of Accession of Romania to the European Union have been the necessary rules for maintaining the economic equilibrium. To remove the growing deficit, after 2008, a pro-cyclical and expansionist policy was applied.

However, the economic crisis that has affected Romania since the last quarter of 2008 has destabilized the long-term business activity of the entire business environment. A set of fiscal rules were necessary in the context of stimulating economic growth. At that time, no fiscal policy was applied to eliminate the effects of the recession as quickly as possible. This was mainly due to decision-makers who did not act to meet the needs of the business environment due to shortcomings in fully understanding the functioning of a market economy.

Table 1 shows the evolution of the types of fiscal rules applied in Romania. Thus, the first fiscal rules referred to the setting of the budget and public debt ceilings, being in fact legislative provisions imposed by the Maastricht Treaty, which had to be respected when Romania joined the European Union as a member state. 
Only in 2010 was adopted the Law on fiscal-budgetary responsibility no. 69/2010 through which the fiscal-budgetary policy was to be carried out according to the first fiscal rules in Romania [18]. For the first time, it was pointed out the necessity of anchoring fiscal policies in a sustainable framework, this element being among the main objectives that the fiscal-budgetary responsibility Law considered. This also prefigured budgetary fiscal discipline and medium and long-term sustainability of public finances as well as establishing a framework of principles and rules on the basis of which the Government could ensure the implementation of fiscal-budgetary policies leading to sound financial management resources. In addition to the three fiscal rules already in place, the fiscal policy conducted in Romania after 2010 has implemented through this law a purely national rule aimed at setting capping rules for budgetary expenditure. The overall increase in total consolidated budget expenditure could not exceed the annual nominal growth rate of gross domestic product until the preliminary consolidated general government balance surplus in the previous year of the year for which the draft budget was developed. This condition was abolished in 2013 when European Union requirements were introduced in the Fiscal Responsibility Law (FRL). The share of personnel costs of the general consolidated budget and of the general government balance in the gross domestic product could not exceed the annual ceilings established by the medium-term fiscal framework, namely for the first two years covered by it. Public debt could be reduced by the difference in the positive balance of the general government budget if it was to be higher than the one projected in that year and in the next two years. Among the objectives pursued under the fiscal-budgetary responsibility law is the need to set up a Fiscal Council to issue opinions and recommendations on official macroeconomic forecasts, annual budget laws and assess the implementation of the new medium-to-long-term fiscal and budgetary strategy. Thus, in the middle of 2010, this Fiscal Council was set up with its role and advisory role on the impact assessment of expenditure, budget rectifications or other important aspects regarding the formation of annual budget.

The aim of these fiscal rules was to ensure medium-term and long-term budgetary equilibrium, as the economy of the country could perform to cover public debt and finance sectors of national interest. Through the Stability and Growth Pact, Romania, like the other European Union Member States, must present in the first months of each year a convergence program that sets its medium and long-term fiscal objectives to maintain an economic balance [19].

In 2012, the Treaty on Stability, Coordination and Governance in the Economic and Monetary Union imposes a new set of fiscal rules on European Union Member States, 
including Romania. This intergovernmental treaty claimed that the budget position of the government to be balanced or surplus. Its medium-term objective specific on country is that the structural deficit in gross domestic product at market prices to be below the lower limit of $0.5 \%$ and if the ratio between government debt and gross domestic product at market prices is significantly lower than $60 \%$, the structural deficit not to exceed the lower limit of $1.0 \%$.

These measures to maintain balance in the economies of the member countries, including economy of Romania, were an external stimulus that required the prospect of the prosperity of the business environment and implicitly, of the society. Particularly in the post-crisis period, these European rules of priority for the fiscal rules at the level of each state generated a general economic equilibrium, focusing in particular on the prospects for medium and long-term sustainable development.

As can be seen in Table 1, from 2013 another set of strictly national rules was implemented by Law no. 377/2013 for amending and completing the Law on fiscalbudgetary responsibility no. $69 / 2010$ [8]. This law was a necessity in order to fulfill the provisions imposed by the Treaty on Stability, Coordination and Governance within the Economic and Monetary Union, while maintaining the structural fiscal objectives.

At the European level, the implementation of national fiscal rules was influenced by the level of economic development and implicitly, by the political factors. Developed countries in Western Europe showed a faster opening to the sustainable development of the economy through the implementation of medium and long-term strategies. Thus, Italy, Spain, France, Belgium, Denmark and Germany are among those developed countries that adopted the fiscal rules before 1993 and had a view on the importance of maintaining an economic balance. In contrast, in eastern European countries belonging to the Eastern bloc, especially the satellite countries, the political actors have played a decisive role in the development of their economy. Communist practice has been an impediment to the expansion of privatization, while limiting the possible transition to a market economy. Communist regimes in Eastern Europe collapsed only at the end of 1989, when both Romania and countries like Bulgaria, Hungary or the Czech Republic gained their economic sovereignty. This political impediment marked the whole economic evolution process, postponing the accession of the eastern countries to the European Union. In this context, they adopted the fiscal rules late, more precisely after 2004, when the transition to the market economy was completed. Because of the incidence of European directives, most Member States have implemented a number of fiscal rules more than three. This is due to the accession to the European Union which, through the Maastricht Treaty, the Treaty concerning the accession or other 


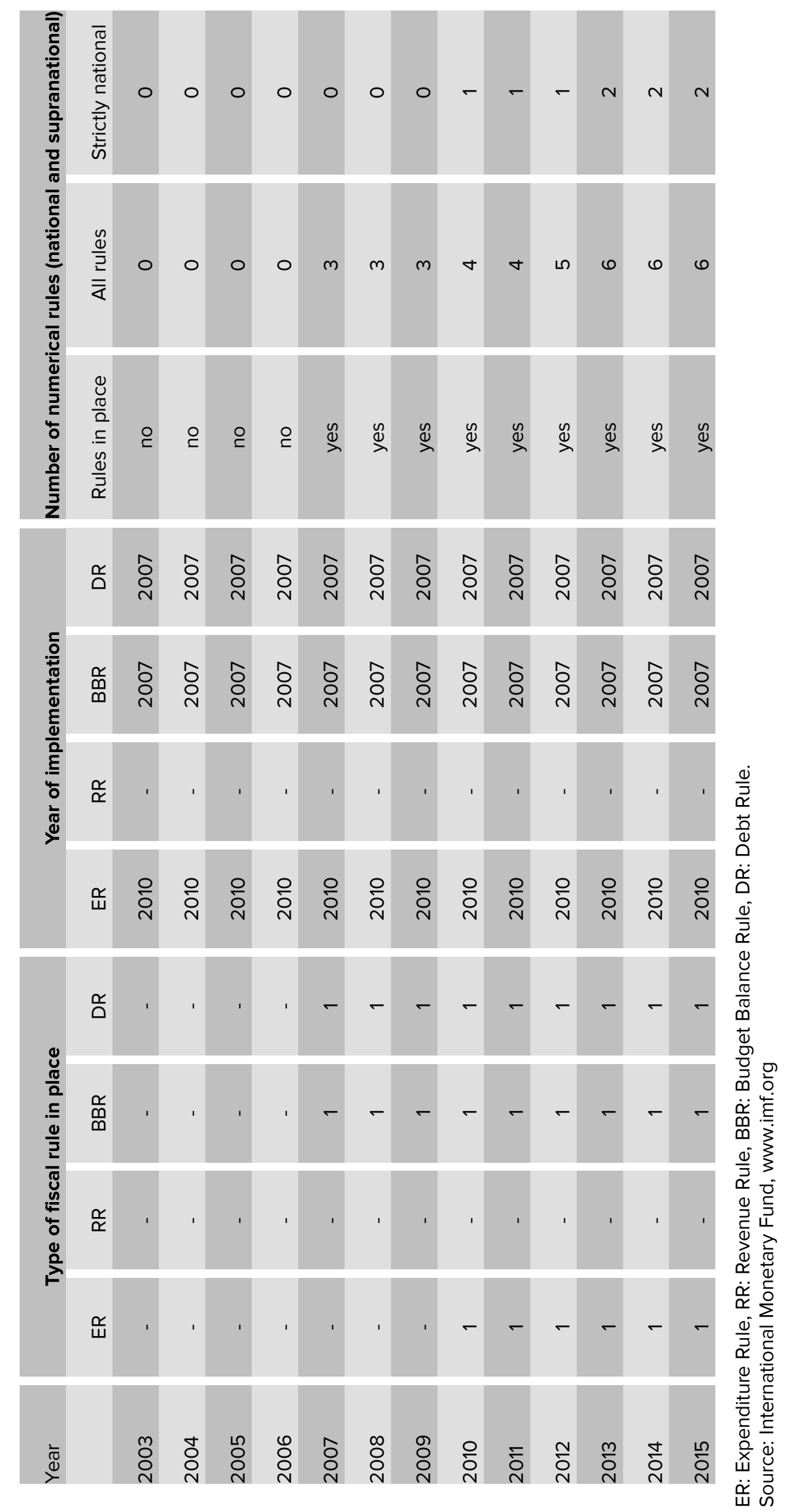


norms, sought to unify the economy at European level [20, 21]. Medium and long-term objectives were the pillars of economic sustainability, with the main goal of maintaining the budget deficit at a certain level.

\section{Analysis of the Fiscal Rules Effects on Fiscal Policy}

Identifying the effect that the implementation of fiscal rules has on the emerging market economy involves understanding epistemological presumptions, locating the main elements of impact on the scale of economic evolution as well as analyzing the significant indicators in completing the overall framework. The procyclical and expansionist policy applied in Romania after 2008 was applied in order to remove the growing deficit. A series of fiscal rules were imposed on government expenditure, structural deficit and public debt at that time, in Romania, while there is currently no rule to refer to government revenues. The tendency of developing countries, like in the case of Romania, is to apply a procyclical policy that focuses on managing budget expenditures. Thus, there will be an increase in budget expenditures in periods of economic expansion proportional to the increase of government revenues. Moreover, there will also be a lack of funding due to the lack of interest in saving in times of impetus. Conversely, periods of economic expansion will only be identified by an accumulation of government debt, which will be recognized as a procyclical policy.

Whereas the present paper aims at identifying how fiscal rules constrain fiscal policy at the level of Romania, we will consider the use of four variables: government expenditures, government revenues, structural deficit and government debt. In order to analyze the effects that they have on applying fiscal policy, we used the estimation of the ARDL, which was implemented by M. H. Pesaran and R. Smith in 1995 and developed by M. H. Pesaran in 1997, M. H. Pesaran and Y. Shin in 1998 and M. H. Pesaran, Y. Shin and R. J. Smith in 2001 [11-14]. Within this model, the Granger causality test will be used to determine the cause-effect relationship between the variables and implicitly to analyze how fiscal rules constrain the fiscal policy applied in Romania.

The ADRL model was created using quarterly data from the first quarter of 2003 and the third quarter of 2018 (63 observations), the data being taken from Eurostat. The variables used to create the model are government revenue (REV), government expenditure (EXP), public debt (DBT) and structural deficit (DEF). In order to overcome the specific government debt seasonality, the adjustment procedure was applied using the TRAMO-SEATS method, the other variables being already seasonally adjusted. All variables were expressed in real terms, in 2010 prices, deflating them by using GDP 
deflator with the base period in 2010 . The variables have been logged for better data distribution, except the DEF variable that is composed of negative values. Application of the ARDL model is more favorable than other models because it allows the use of both variables that are stationary at $\mathrm{I}(0)$ and the variables that become stationary after applying the first difference I(1). The variables that become stationary at the second difference I(2) are not accepted in this model. Table 2 shows the result of the Augmented Dickey-Fuller test for the initial variables and the first order differences. In the case of the REV, EXP and DBT variables, the test rejected the null hypothesis and became stationary only after the first difference. The DEF variable is stationary at level, as the null hypothesis is accepted, the statistical value of the time series being at a significance level of less than 0.05 .

TABLE 2: The result of the Augmented Dickey-Fuller and Phillips-Perron tests for the initial variables and the first differences.

\begin{tabular}{|l|c|c|c|c|} 
Variables & $\begin{array}{c}\text { Statistic value of } \\
\text { the series in } \\
\text { levels }\end{array}$ & $\begin{array}{c}\text { Rejection HO up } \\
\text { to 95\% }\end{array}$ & $\begin{array}{c}\text { Statistic value of } \\
\text { the series in first } \\
\text { differences }\end{array}$ & $\begin{array}{c}\text { Rejection HO up } \\
\text { to 95\% }\end{array}$ \\
\hline REV & $\begin{array}{c}\text { Augmented Dickey-Fuller test-HO has a unit root } \\
\text { EXP }\end{array}$ & No & 0.0001 & Yes \\
\hline DBT & 0.4607 & No & 0.0000 & Yes \\
\hline DEF & 0.6488 & No & 0.0454 & Yes \\
\hline
\end{tabular}

Source: Author's own work

It is necessary to determine the optimal number of lags for correct model processing. Based on the Akaike information criterion and the Schwarz information criterion, a number of 4 lags was chosen, the results was presented in Table 3. Choosing the optimal number of lags was done by determining the lowest value between the two criteria. Thus, it can be seen that the Akaike information criterion has the lowest specific value for lag 4.

Testing the cointegration relationship between the model variables will be demonstrated by applying the Bounds test. Table 4 presents critical values at the significance level of $1 \%, 2.5 \%, 5 \%$ and $10 \%$. Whereas these values are lower than the F-statistic value of 6.69 it can be stated that there is a long-term cointegration relationship between the model variables. The null hypothesis of the cointegration relationship between DBT and the other model variables (EXP, REV and DEF) was rejected.

Table 5 shows a strong connection between public debt, government revenue and government expenditure. Thus, a $1 \%$ increase in government expenditure leads to a $67,86 \%$ increase in public debt and a $1 \%$ increase in government revenue leads to a decrease in public debt by $61,98 \%$. This is due to the lack of fiscal rules applicable on 
TABLE 3: Lag order selection criteria.

\begin{tabular}{l|c|c|}
\hline Lag & AIC & SC \\
\hline 0 & 12.12108 & 12.26445 \\
\hline 1 & 6.972373 & $7.689233^{*}$ \\
\hline 2 & 6.521208 & 7.811556 \\
\hline 3 & 6.449883 & 8.313720 \\
\hline 4 & $6.437213^{*}$ & 8.874537 \\
\hline 5 & 6.479895 & 9.490707 \\
\hline${ }^{*}$ indicates lag order selected by the criterion & \\
\hline AlC: Akaike information criterion & & \\
\hline SC: Schwarz information criterion & & \\
\hline
\end{tabular}

Source: Author's own work

TABLE 4: Bounds Test for cointegration analysis.

F-Bounds Test
Test Statistic
F-statistic

Value

6.694010

\begin{tabular}{|c|c|c|}
\hline \multicolumn{3}{|c|}{ Null Hypothesis: No levels relationship } \\
\hline Signif. & $\mathrm{I}(0)$ & $\mathrm{I}(1)$ \\
\hline $10 \%$ & 2.37 & 3.2 \\
\hline $5 \%$ & 2.79 & 3.67 \\
\hline $2.5 \%$ & 3.15 & 4.08 \\
\hline $1 \%$ & 3.65 & 4.66 \\
\hline
\end{tabular}

Source: Author's own work

government revenues. In this regard, it would be possible to balance the public debt response to the government expenditure shock and fiscal revenue.

TABLE 5: ARDL coefficients for long-run.

Variable
EXP
REV
DEF

\begin{tabular}{|c|}
\hline Coefficient \\
\hline 67.86697 \\
\hline-61.98487 \\
\hline 0.001163 \\
\hline
\end{tabular}

\begin{tabular}{|c|}
\hline Std. Error \\
\hline 31.57354 \\
\hline 30.32202 \\
\hline 0.000569 \\
\hline
\end{tabular}

t-Statistic

2.149489

$-2.044220$

2.041881

Source: Author's own work

Table 6 of regression shows that there is a negative but insignificant relationship between DBT, EXP, REV and DEF on the short-term. The coefficient of the error correction term $(-0,042)$ is significant at $1 \%$. The error correction model is used to identify whether there is a short-term relationship between the model variables. The error correction term in this model shows that the return to equilibrium in the event of an imbalance will be achieved at an adjustment rate of $4,2 \%$. This assertion can be transposed by the fact that only $4,2 \%$ of errors of the previous year will be corrected in the current year. The discrepancies between long-term and short-term results demonstrate 
the instability of the Romanian fiscal system as well as the lack of a strategy to help the economy of the country withstand a short-term impact.

TABLE 6: Error Correction Representation of the Selected ARDL $(4,4,1,4)$ Dependent Variable $\Delta$ DBT.

Variable
$\Delta$ EXP
$\Delta$ REV
$\Delta$ DEF
ECM(-1)

\begin{tabular}{|c|}
\hline Coefficient \\
\hline 1.338523 \\
\hline-1.232418 \\
\hline $2.52 \mathrm{E}-05$ \\
\hline-0.042431 \\
\hline
\end{tabular}

Std. Error
0.552086
0.533185
$1.12 E-05$
0.007008

t-Statistic

2.424486

$-2.311424$

2.251166

$-6.054558$

Source: Author's own work

The Breusch-Godfrey Serial Correlation LM Test and Heteroskedasticity Test: ARCH were applied. These tests indicate that there is no serial correlation and heteroskedasticity, demonstrating that the model is in the normal parameters. The verification of model stability regarding the relationship between the DBT, EXP, REV and DEF variables over both the long and short-term will be achieved by applying the CUSUM and CUSUM of squares tests to a $5 \%$ significance level. The validity of the model is demonstrated by the position of the CUSUM line that has to be positioned between the significance level lines. In Figure 1, it can be seen that the blue line is positioned between the significance level lines, which shows that there is a long-term stability between the variables in the model.

To verify the time stability of the model, the CUSUM of squares test presented in Figure 2 was applied., It can be seen from the figure shown that the blue line is between the significance level lines except for a short period, insignificant for the model. However, it can be said that the model is stable and the application of the Granger causality test will be possible.

Whereas the model fulfills all the conditions of stability, we will proceed to the Granger causality test for identifying cause-effect relationships between the four variables of the model. It will be possible to create an overview of the fiscal rules imposed and whether they influence the procyclical fiscal policy in Romania by applying the causality test. A causal relationship was identified based on the information in Table 7 and obtained by applying the Pairwise Granger Causality Test. This can only be verified if the $p$-value is less than the $5 \%$ significance level.

Two feedback systems were identified EXP causing DBT and vice versa, respectively REV causing DBT and vice versa. An increase in government expenditure may cause an increase in public debt, but also an increase in public debt may cause an increase in government expenditure. This cause-effect relationship is also observed in the case 


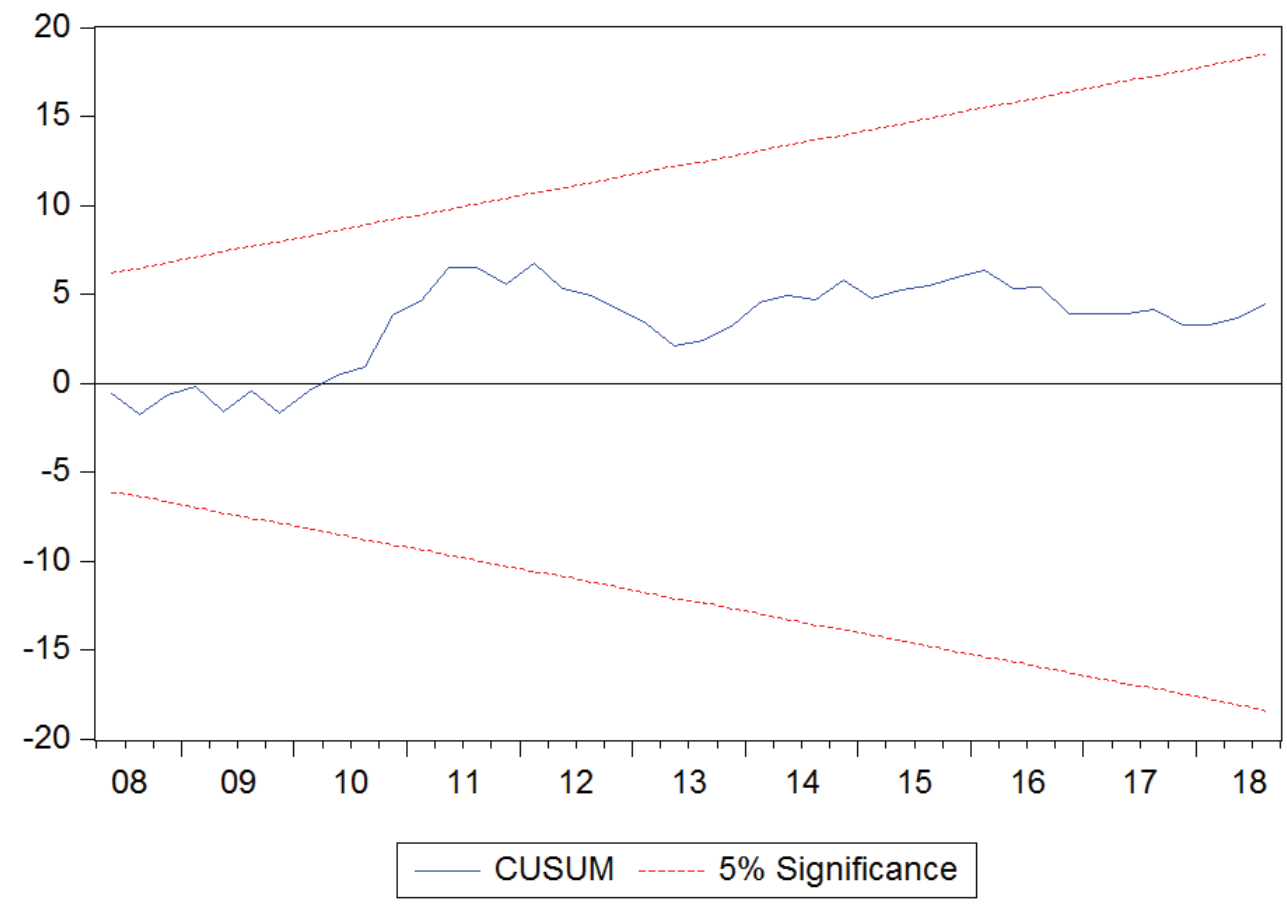

Figure 1: CUSUM stability test (Source: Author's own work).

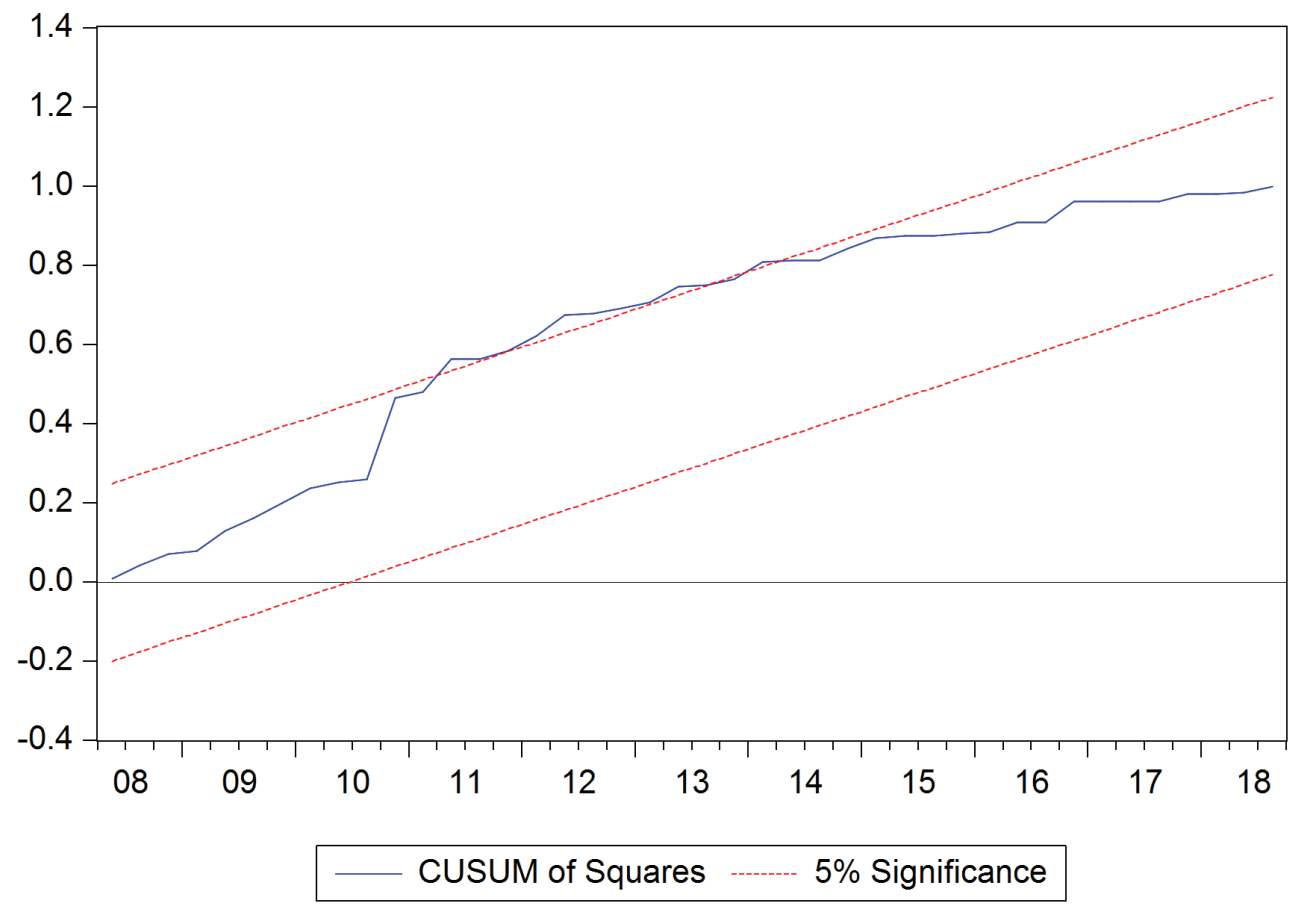

Figure 2: CUSUM of Squares stability test (Source: Author's own work). 
of government revenue that led to an increase in public debt and vice versa. This interdependence between variables reveals a strong influence of fiscal rules that constrain fiscal policy at Romania level.

In the third causal relationship, DEF causes DBT to a $p$-value of 0,021 . REV variable causes EXP to a $p$-value of 0,0142 . The last causal relationship has been identified for the DEF and EXP variables at a $p$-value of 0,0386, but EXP does not cause DEF. Thus, an unidirectional causal link from DEF towards DBT, REV and EXP was identified as well as two bidirectional links in which EXP causes DBT and vice versa, respectively REV causes DBT and vice versa.

TABLE 7: Granger causality test.

Null Hypothesis:
EXP does not Granger Cause DBT
DBT does not Granger Cause EXP
REV does not Granger Cause DBT
DBT does not Granger Cause REV
DEF does not Granger Cause DBT
DBT does not Granger Cause DEF
REV does not Granger Cause EXP
EXP does not Granger Cause REV
DEF does not Granger Cause EXP
EXP does not Granger Cause DEF
DEF does not Granger Cause REV
REV does not Granger Cause DEF

\begin{tabular}{|c|c|c|}
\hline Obs & F-Statistic & Prob. \\
\hline 59 & 6.20384 & 0.0004 \\
\hline 7 & 2.45122 & 0.0580 \\
\hline 59 & 6.19178 & 0.0004 \\
\hline & 4.33307 & 0.0044 \\
\hline 59 & 3.21105 & 0.0201 \\
\hline & 2.25710 & 0.0761 \\
\hline 59 & 3.46497 & 0.0142 \\
\hline & 0.78666 & 0.5393 \\
\hline 59 & 2.74198 & 0.0386 \\
\hline & 1.07679 & 0.3780 \\
\hline 59 & 0.76149 & 0.5553 \\
\hline
\end{tabular}

Source: Author's own work

The results obtained are consistent with those identified by C. Nerlich and W. H. Reuter and by V. Grembi, T. Nannicini and U. Troiano, which found that fiscal rules countered the applicability of procyclical fiscal policy $[6,10]$. Although the fiscal policy implemented in Romania is a procyclical and expansive one, focused on the management of government expenditure and the elimination of the deficit, the fiscal rules implemented at both national and European level have influenced its application. According to the unidirectional link, the deficit will cause public debt, which will cause revenue. Thus, government expenditure is the only variable that does not cause any other variable. This may explain the fact that a government expenditure management according to the fiscal policy applied in Romania was not possible. One of the main causes is the application of the fiscal rules which imposed a deficit management rule from 2007, as a part in the Protocol on the excessive deficit procedure. 


\section{Conclusions}

This study aimed to identify the possibility as the fiscal rules, both national and European, to constrain fiscal policy in Romania. The results revealed a long-term relationship between public debt, government expenditure, tax revenue and deficit. However, the short-term relationship between variables of the model is almost nonexistent, demonstrating the instability of the Romanian fiscal system, as well as the inability of the economy to recover in the event of a shock. In order to determine the causal relationship, the Granger causality test was applied to identify a unidirectional link from deficit to public debt, government revenue and government expenditure. This proves the constraint of the fiscal rules to apply the procyclical fiscal policy. Although the procyclical fiscal policy aimed to manage expenditure, the European fiscal rules implemented in Romania with its accession as a Member State were mainly focused on deficit management. This also resulted from analysis that government expenditure can only cause an increase or decrease in public debt, the causal relationship being preceded by all other variables.

The late transition to the market economy, the implications of a legislative framework that is not adapted to the dynamics of the Romanian economy, as well as the fiscal rules inconsistent with the applied fiscal policy are the main factors that mitigated the possible economic advance of this country.

Romania, like most emerging countries, applies a procyclical fiscal policy. However, in Romania fiscal rules constrain the fiscal policy applied to balance the economy. An analysis of other emerging countries could identify trends in the applicability of fiscal rules and their constraints on fiscal policies. The results helped to identify how the fiscal rules implemented in Romania compelled the applicability of fiscal policy. Previous research demonstrated the effect of interconnection between them in some emerging countries, but no analysis of their impact in Romania was made. Thus, identifying the main cause that impedes the manifestation of fiscal policy gives decision-makers the power to focus on reassessing existing fiscal rules in terms of government expenditure and public debt management so that the Romanian economy can cope with the unexpected crisis situations. The research highlighted that fiscal rules constrain fiscal policy in Romania, but it has certain limits represented by the incidence of other fiscal policy factors that will be the subject of future research. 


\section{References}

[1] Bova, M.E., Carcenac, N. and Guerguil, M.M. (2014). Fiscal rules and the procyclicality of fiscal policy in the developing world. No. 14-122, International Monetary Fund.

[2] Cordes, T., Kinda, M.T., Muthoora, M.P.S. and Weber, A. (2015). Expenditure rules: effective tools for sound fiscal policy?, No. 15-29, International Monetary Fund.

[3] Combes, J.L., Minea, A. and Sow, M. (2017). Is fiscal policy always counter-(pro)cyclical? The role of public debt and fiscal rules. Economic Modelling, no. 65, pp. 138-146.

[4] Dziemianowicz, R.I. and Kargol-Wasiluk, A. (2015). Fiscal Responsibility Laws in EU Member States and Their Influence on the Stability of Public Finance. International Journal of Business and Information, vol. 10, no. 2, pp. 153-179.

[5] Dumitrescu, B.A. (2015). The Fiscal Framework In Romania--The Efficiency Of Fiscal Rules. Financial Studies, vol. 19, no. 3, pp. 91-106.

[6] Grembi, V., Nannicini, T. and Troiano, U. (2016). Do fiscal rules matter?. American Economic Journal: Applied Economics, pp. 1-30.

[7] Keynes J.M. various dates. The Collected Writings of John Maynard Keynes. Volume IX, Essays in Persuasion. Vol. XXI, Activities 1931--1939, World Crises and Policies in Britain and America, edited by Donald Moggridge. Vol. XXV, Activities 1940--1944, Shaping the Post-War World: The Clearing Union, edited by Donald Moggridge. Vol. XXVI, Activities 1941--1946, Shaping the Post-War World: Bretton Woods and Reparations, edited by Donald Moggridge. London: Macmillan Co.

[8] Law no. 377/2013 for amending and completing the Law on fiscal-budgetary responsibility no. 69/2010.

[9] McManus, R. and Ozkan, F.G. (2015). On the Consequences of Pro-Cyclical Fiscal Policy. Fiscal Studies, vol. 36, no. 1, pp. 29-50.

[10] Nerlich, C. and Reuter, W.H. (2015). Fiscal rules, fiscal space and procyclical fiscal policy. No. 1872, ECB Working Paper.

[11] Pesaran, M.H., (1997). The role of economic theory in modelling the long run. The Economic Journal, vol. 107, no. 440, pp. 178-191.

[12] Pesaran, H.H. and Shin, Y. (1998). Generalized impulse response analysis in linear multivariate models. Economics letters, vol. 58, no. 1, pp. 17-29.

[13] Pesaran, M.H., Shin, Y. and Smith, R.J. (2001). Bounds testing approaches to the analysis of level relationships. Journal of applied econometrics, vol. 16, no 3, pp. 289-326. 
[14] Pesaran, M.H. and Smith, R. (1995). Estimating long-run relationships from dynamic heterogeneous panels. Journal of econometrics, vol. 68, no. 1, pp. 79-113.

[15] Suzuki, Y. (2015). Sovereign risk and procyclical fiscal policy in emerging market economies. The Journal of International Trade \& Economic Development, vol. 24, no. 2, pp. 247-280.

[16] Socol, A.G. and Feraru, R.M. (2017). The role of fiscal policy in the financial crisis. Challenges and solutions. Theoretical \& Applied Economics, vol. 24, no. 2, pp. 5-20.

[17] Šehović, D. (2015). The Impact of the Great Recession on Monetary and Fiscal Policy in Developed Market Economies. Business systems research journal: international journal of the Society for Advancing Business \& Information Technology (BIT), vol. 6, no. 1, pp. 56-71.

[18] The fiscal-budgetary responsibility law no. 69/2010.

[19] The Stability and Growth Pact, 1997.

[20] Treaty concerning the accession of the Republic of Bulgaria and Romania to the European Union, 25 April 2005.

[21] Treaty on European Union, Maastricht, Netherlands, 7 February 1992.

[22] Treaty on Stability, Coordination and Governance in the Economic and Monetary Union, 2012. 